\title{
Extrahepatic Bile Duct Embryonal Rhabdomyosarcoma
}

National Cancer Institute

\section{Source}

National Cancer Institute. Extrahepatic Bile Duct Embryonal Rhabdomyosarcoma. NCI

Thesaurus. Code C5847.

An embryonal rhabdomyosarcoma that arises from the extrahepatic bile ducts. 